\title{
Teoría del intermezzo: formas intersticiales de leer Material rodante, de Gonzalo Maier
}

\author{
Theory of intermez:o: In-between approaches for reading Material \\ rodante by Gonzalo Maier
}

\author{
Felipe Adrián Ríos Baeza \\ Universidad Anáhuac Querétaro, México \\ feliperios.ffyl@gmail.com
}

\section{Resumen}

Empleando nociones del enfoque poscolonial y posmoderno, este trabajo propone realizar una lectura más atenta de la novela Material rodante (Minúscula, 2015), del escritor chileno Gonzalo Maier (Talcahuano, 1981), construyendo una particular conceptualización para ello: la teoría del intermez:o (o intermedio, intersticio), al presentarse en este libro cierta analogía con la estructura del drama. En Material rodante esa intermedialidad cruza también la pregunta por la identidad (aunque paródica y finalmente desestimada), la espacialidad (un tren que va de Bélgica a Holanda y viceversa) y el argumento mismo. Aunque parece que se realiza un viaje reiterado, insustancial, que emerge como bucle poco significativo entre las ciudades de Lovaina y Nijmegen, Maier no solamente consigue, como ha comentado la crítica anterior, una novela digresiva, sino una esquematización de sus propias formas narrativas, asunto que ya venía articulándose en algunas zonas de Leyendo a Vila-Matas (2011), y que permeará, también, su obra posterior. Es por ello que, en un momento del ensayo, resulta importante el análisis comparatista que establecemos entre Material rodante y ciertas zonas de la obra del mencionado Enrique Vila-Matas, pues permitirá comprender mejor de dónde germinan y hacia dónde avanzan las búsquedas formales del propio Maier.

Palabras clave: Gonzalo Maier, narrativa posmoderna, intersticio.

\begin{abstract}
Using the notions from the postcolonial and postmodern approaches, this work tries to perform a more precise reading of the novel Material rodante (Minúsula, 2015) by the Chilean writer Gonzalo Maier (Talcahuano, 1981), building a particular conceptualization for this: the theory of intermezzo (or in-between, or interstice) when this book presents some analogy with the dramatic structure. In Material rodante,
\end{abstract}


this intermezzality crosses through the interrogative of identity (although paradoxically and finally discarded) the concept of space (traveling from Belgium to the Netherlands and back), and the argument itself. Even when it seems that it is a repetitive an insusbstantial trip, that emerges as an insignificant loop between the cities of Lovaina and Nijmejen, Maier does not only achieve a disgresive novel, as previous critics have pointed out, but a schematization of his own narrative forms, which had been articulating in some parts of Leyendo a Vila-Matas (2011) and will permeate, also, into his later work. That is why, at one point in the essay, the comparative analysis that we establish between Material rodante and certain areas of the work of the aforementioned Enrique Vila-Matas is important, since it will allow a better understanding of where the formal searches of Maier are germinating from and moving towards.

Keywords: Gonzalo Maier, postmodern narrative, in-between.

Recibido: 28/05/2020

Aceptado: $12 / 10 / 2020$

En su conocido libro The Location of Culture (El lugar de la cultura, 1994), Homi Bhabha se apropiaba de la obra plástica y performática de artistas, como la afroamericana Renée Green o el puertorriqueño Pepón Osorio, para afirmar que la estética contemporánea pone un especial acento en aquellas zonas liminales, transitables de manera ambivalente, y donde se establecerían los entrecruzamientos propios de la cultura por venir. Así, espacios como escaleras y puentes, por ejemplo, permitirían atender no tanto a los lugares estables y reconocidos (lo que está arriba y lo que está abajo; lo que está a la izquierda y lo que está a la derecha) sino a la interacción dinámica y compleja que se da en lo que él llama intersticio (in-between):

La escalera como espacio liminal, entre-medio de las designaciones de identidad, se torna el proceso de la interacción simbólica, el tejido conectivo que construye la diferencia entre lo alto y lo bajo, entre negro y blanco. El movimiento de la escalera, el movimiento temporal y el desplazamiento que permite, impide que las identidades en los extremos se fijen en polaridades primordiales. Este pasaje intersticial entre identificaciones fijas abre la posibilidad de una hibridez cultural que mantiene la diferencia sin una jerarquía supuesta o impuesta ... Es en este sentido que el límite se vuelve el sitio desde el cual algo comienza su presentarse en un movimiento no distinto a la articulación ambulante y ambivalente del más allá que he trazado. . . Siempre, y siempre de modo diferente, el puente acompaña la marcha más rápida o más lenta de los hombres en una dirección o en otra, de modo que puedan llegar a las otras orillas ... El puente reúne como un paso que cruza (20-21). 
Trasladando esta idea al campo de la literatura, en la teoría de Bhabha los puentes y escaleras abandonan su dimensión fenoménica y se vuelven conceptos mediante los cuales entender que la identidad, más que una institución monolítica, se trata de un perpetuo forzamiento de los límites epistemológicos para comprender pensamientos y conductas de distintos escritores y sus personajes. Analizando la obra de Toni Morrison, John M. Coetzee, Salman Rushdie y Nadine Gordimer, entre otros, Bhabha comprende que ese in-between, o intersticio, representa, por su carga vívida y su potencial de transformación, el único lugar donde volver a hacerse la pregunta por la identidad. El in-between es punto de llegada de todas las confluencias culturales, étnicas, políticas y estéticas, y a la vez un punto de partida desde donde erigir un sujeto más complejo, que rompe, sobre todo en términos sociales, el principio de no contradicción europeo: "[D]ebemos recordar que es el "inter" (el borde cortante de la traducción y negociación, el espacio inter-medio (in-between)) el que lleva la carga del sentido de la cultura" (59). Y más adelante, afirma: "[L]a cuestión misma de la identificación sólo emerge entre-medio [in-between] de la renegación y la designación. Es realizada en el combate agonístico entre la demanda visual, epistemológica de un conocimiento del Otro y su representación en el acto de la articulación y la enunciación" (72).

Estos planteamientos de Homi Bhabha, más otras nociones auxiliares de Lucien Dällenbach, Jean Cohen y de la física cuántica, ayudarán a realizar una lectura más precisa de la novela Material rodante (Minúscula, 2015), del chileno Gonzalo Maier (Talcahuano, 1981). Aquí la pregunta por la identidad (aunque paródica y, como se verá, finalmente desestimada) se lleva a cabo en otro espacio intersticial, un tren que va de Bélgica a Holanda y viceversa. Pero, aunque parece que se realiza un viaje reiterado, insustancial, que emerge como bucle poco significativo entre las ciudades de Lovaina y Nijmegen, Maier consigue no solamente, como ha comentado la crítica, una novela digresiva, sino una conceptualización de sus propias formas narrativas, asunto que ya venía articulándose en algunas zonas de Leyendo a Vila-Matas (2011) y que permeará, también, El libro de los bolsillos (2016), Hay un mundo en otra parte (2018) y Otra novelita rusa (2019). Esa conceptualización tomará el nombre, para este estudio, de "teoría del intermezzo", al tratarse en algunos episodios de una división que remite a la estructura del drama teatral (únicamente alusiva a los actos e intermezzos), y permitirá darle una interpretación más ajustada a la novela, asumida con cierta liviandad por un sector de la crítica literaria.

Patricia Espinosa, por ejemplo, señala que Maier, en Material rodante, "propone un juego donde el concepto de inutilidad es tematizado y a partir del cual tanto el acto de narrar como lo narrado podrían ser parte del universo de lo prescindible" (92), mientras que Francisco Solano afirma que: "Maier habla mucho de su condi- 
ción de viajero, pero poco de sí mismo (y si lo hace tiende a lo burlesco); además, no sólo acredita una sosegada inclinación al asombro eludiendo la repetición, sino que invita al lector a ver la fertilidad de las horas muertas" (párr. 1). Con cierto alcance mayor, Pablo Sebastián dice que en la novela de Maier prima el "detenerse en detalles sin buscar una causa, sino sólo acumular más minutos de observación y reflexión, de no dejar de aprender a mirar con curiosidad" (párr. 3).

En contraposición, creemos que el trayecto que va de Lovaina a Nijmegen es de lo único que Maier no puede prescindir, porque dicho trayecto articulará una estructura narrativa que tanto narrador como historia necesitan para poder funcionar; y tanto la "elusión a la repetición" como la invitación a ver la "fertilidad de las horas muertas" — es decir, los intersticios — representan afirmaciones hechas tras una lectura muy apresurada del libro. Maier repite, y repite mucho, con plena conciencia, que sólo en la infertilidad de las horas muertas es posible hallar, si acaso, un lugar de enunciación y una identidad que rocen la perfección. "La espera es un deporte psicológico y de largo aliento" (33), comenta en un punto, lo que permite entender, también, una de las partes más chuscas, pero no menos imprescindibles de la novela: la defensa que hace el narrador de los pijamas: "[L]a verdadera utilidad del pijama está en ayudarnos a alcanzar la perfección, es decir, a no hacer nada ... Por eso, en nombre del ocio, pónganse lo que les quede más cómodo, estiren las extremidades y vean como la vida pasa por delante de sus ojos" (82-83).

\section{La mirada del lenguado: hipotextos germinativos vilamatasianos}

Como se señalaba, ya en Leyendo a Vila-Matas, novela de 2011, publicada por la editorial LOM, se encuentra en estado germinativo la "teoría del intermezzo" que aquí se propone. Dicha teoría vertebrará todo Material rodante y encuentra corrientes ni siquiera secretas, sino muy explícitas, con al menos tres libros del mencionado autor barcelonés que operarán como "hipotextos", según la conocida teoría de Gérard Genette: Bartleby y compañia, Doctor Pasavento y Dublinesca. Ese Maier viajero llega a Barcelona buscando a uno de sus referentes más directos, Enrique Vila-Matas; pero en su intento da con el mar Mediterráneo (es decir, se encuentra como un espacio limítrofe, un cambio de elemento vital que permite, en una estrategia narrativa muy posmoderna, que el objetivo inicial del viaje se diluya al no alcanzar clímax alguno). Al final, hace dos afirmaciones: primero, sobre su condición de pasajero de tren, que no viajero (asunto que también en Material rodante aparecerá con insistencia): "Viajando los días se vuelven más largos, más detallados" (Pos 394); y segundo, sobre su condición de excritor, en el abandono total de sus pretensiones apremiantes por ser un autor al uso: 
Después de diez años leyéndolo me dije que el mejor funeral que le podía dar a mi carrera de novelista era escribir sobre Vila-Matas . . Lo hago porque precisamente no soporto el miedo al fracaso, a que ni mi libro sobre Vila-Matas resulte. En otras palabras: que todo esto no es más que la encarnación del miedo a no poder ser siquiera un escritor renunciado. Un excritor (Pos 636 - Pos 652).

La corriente secreta, por supuesto, de Leyendo a Vila-Matas es la novela-ensayo Bartleby y compañia (1997), aquel libro de Vila-Matas donde un burócrata jorobado pide unos días de baja en el trabajo para escribir un "diario que va a ser al mismo tiempo un cuaderno de notas a pie de página que comentarán un texto invisible y que espero que demuestren mi solvencia como rastreador de bartlebys" (11). Los bartlebys son aquellos excritores, como Rimbaud, Juan Rulfo o J. D. Salinger, quienes precisamente, en algún momento de sus carreras, vieron que por miedo, desidia o imposición externa, la vocación literaria los abandonaba. La cita final de Maier no hace más que confirmar que la novela completa se ha elaborado para entrar en el canon de esos bartlebys, teniendo como proyectos fracasados el conocer a Vila-Matas, por un lado, y escribir un libro sobre él, por otro. Al no concretarse ninguno de los dos objetivos, Leyendo a Vila-Matas es la alineación de Gonzalo Maier con Vila-Matas en el intento de este por abandonar la pretensión de hacer literatura mimética y abocarse a la escritura de textos que parezcan diarios, apuntes personales y ensayos de opinión trufados de conexiones arbitrarias con diversos focos de la cultura; textos donde quepa todo un anecdotario personal, real o inventado, con referencias que sólo se confirman en las páginas de otros libros. Es decir, el ingreso a un tipo de creación que abandona los espacios estáticos (actos) para ingresar en aquellos intersticios liminales donde, paradójicamente, aunque la acción dé paso a la reflexión, hay una carga cultural muchísimo más dinámica (intermezzo).

Si Leyendo a Vila-Matas surgía de Bartleby y compañia, el hipotexto de Material rodante es doble: Doctor Pasavento, mayormente, y Dublinesca, en menor medida. Creemos que la premisa del breve libro de Gonzalo Maier se desprende, de hecho, de un solo párrafo del Doctor Pasavento; uno solo que el narrador de Material rodante espejea y resignifica:

Pensé en la tan socorrida figura literaria de la fugacidad de los paisajes de ventanilla de tren. Y también en la literatura misma y en que precisamente la característica más notable de ésta consistía en escapar a toda determinación esencial, a toda afirmación que la estabilizara, pues uno nunca podía fijarla en un punto cierto, siempre había que encontrarla o inventarla de nuevo. Pensé 
en esto mientras el tren avanzaba con velocidad de ave rápida dejando atrás estaciones con nombres de pueblos imposibles (20-21).

También en la novela de Maier vemos a un personaje —un burócrata que ha abandonado sus intenciones literarias y académicas; un chileno desarraigado que viaja, lee y anota impresiones en un computador portátil- y que constantemente, en el viaje repetitivo entre Bélgica a Holanda, intenta ajustar la visión frontal que tiene de lo que sucede dentro del vagón con la visión periférica del paisaje, visión que de manera acertada y sarcástica es descrita como una "vista lateral y pasiva, que es un premio de consuelo extraño en el que se mira como los lenguados, así, de lado, como si el viaje en tren fuera una foto en dos dimensiones" (85). El tema de la visión lateral, o la "mirada del lenguado", para usar su propia imagen, es fundamental para entender la estructura narrativa de Material rodante. La intención inicial es describir no los momentos muertos de los viajes, como lo ha marcado la crítica anterior, sino un descubrimiento pasmoso: la inactividad es una de las caras más acertadas de la perfección. Al parecer, de eso debía tratar Material rodante, en un inicio, y así lo marca el epígrafe de Roald Amundsen, "la aventura es señal de incompetencia” (7). No obstante, este narrador saboteará la posibilidad de erigir un tratado al respecto, así como el de Leyendo a Vila-Matas sabotea la posibilidad de escribir un estudio sobre el autor catalán, volviéndose de este modo un bartleby más.

Cuando se encuentren todas las condiciones dadas para conjeturar y argumentar que la quietud es sinónimo de excelencia, el narrador mirará por la ventanilla y el relato, en términos de velocidad y planteamiento, se dislocará, trayendo a la narración asuntos que son parte de su visión periférica del mundo físico (una araucaria en Etten-Leur, letreros de neón, unas huertas comunitarias llamadas volkstuinen) y luego periférica del mundo metafísico (los recuerdos de viajes con amigos, una máquina de golosinas que se traga monedas en la estación de Roosendaal o sus lecturas de autores que también están en el canon vilamatasiano, como Cees Nooteboom, Walter Benjamin, Samuel Beckett o Georges Perec). Lo que ve el narrador por la ventana le permitirá la asociación libre con determinados referentes cultos con el fin de que, a falta de una historia progresiva, el relato pueda proseguir (la mención, por ejemplo, a los volkstuinen provoca un comentario a Henry David Thoreau, y este comentario conectará con el lado más naíf del romanticismo alemán, con videojuegos como Minecraft y, finalmente, con una confirmación de que no hay novela fuera del tren, lo que equivale a decir que no existiría una narración fuera del universo de estos intermezzos teatrales: "Tal vez la internet de alta velocidad, la pasiflora en gotas y el acceso democrático al whisky irlandés sea un precio 
justo por vivir en un edificio mal tenido, con una aislación pobre y sin poder escapar de este tren que va de un lado a otro" (25. La cursiva es nuestra).

Los detalles, entonces, como adelantaba Pablo Sebastián, no solidifican el supuesto tema principal (la quietud como expresión de la perfección), sino que brotan para desordenar cualquier estructuración tradicional en el relato. Es por eso que muy al principio del libro, cuando el narrador que mira como lenguado repara en una araucaria en medio de una ciudad holandesa llamada Etten-Leur, dicha referencia no sólo actuará como una anomalía en el paisaje, sino como metatexto singular de la propia literatura de Maier: "Tenía las ramas como paraguas invertidos, apuntando hacia el cielo, pero el único detalle fuera de lugar - y en los detalles vive el diablo- es que el árbol no estaba en medio de un bosque en Coñaripe" (Maier 18). Una araucaria fuera de lugar representa, pues, la exacta condición de identidad para un chileno que hace un recorrido intersticial entre dos países europeos. ${ }^{1}$ Adicionalmente, el modo en que se narrará la llegada de dicha araucaria al territorio holandés será el mismo modo en que Maier hará germinar Material rodante: un pequeño piñón plantado de manera extravagante en un territorio que no es el suyo. Justo en los detalles, vistos como de paso, está la singularidad y esencialidad literaria de este libro.

Un momento, de hecho, que confirma la focalización en los intersticios, y en el modo adecuado de narrarlos según esta teoría que hemos erigido, es cuando en Lovaina, antes de tomar el tren, el narrador avanza en bicicleta muy temprano y se topa con personas que apenas están despegándose la noche del cuerpo:

A veces una pareja está en la esquina, abrazándose medio borracha, y ella le agarra el poto y le da un beso y se quedan mirando con los ojos tan abiertos, tan jóvenes, mientras uno avanza en bici sin poder detenerse a adivinar cómo terminará la escena, aunque el final de una noche de amor, ciertamente, nunca esconde tantos misterios como el comienzo (52).

Lo que supondría otra forma de decir que planteamientos, nudos y desenlaces ya importan poco en la obra de Maier, uno de los lectores más dotados de Vila-Matas,

1 La misma impresión tiene el crítico Roberto Careaga, quien señala: "Podría decirse que Maier se va por las ramas, pues literalmente hay un tronco en este libro: el de una araucaria del sur de Chile creciendo sin pausa en una ciudad perdida de Holanda ... En esa declaración yo leo dos cosas: al verdadero Maier escribiendo, lo que por supuesto da lo mismo, y —esto importa más — una refutación de la novela tradicional. Contar una historia, llevarla adelante durante cientos de páginas, más aún si está basado en hechos reales, sería un despropósito en la estética de Maier" (párr. 17-18). 
y que, en términos de la teoría narrativa de Barthes, ${ }^{2}$ será en las funciones catálisis y no en las cardinales donde emergerá lo esencial. En dichas funciones es donde se extraerá, metaliterariamente, el modo en que se construye esta novela: "Mi consuelo", dice en un momento el narrador, "es que estas digresiones realmente no son sobre trenes sino sobre viajes. Y mejor: sobre viajes repetidos” (90).

Aquí, al parecer, la novela de Vila-Matas que Maier lee con fruición es Dublinesca (2010). Recordemos que Samuel Riba, el protagonista de dicho libro, se autodesigna como el último editor culto y literario, que "[t]iene una notable tendencia a leer su vida como un texto literario, a interpretarla con las deformaciones propias del lector empedernido que ha sido durante tantos años" (12). Eso hará, precisamente, el pasajero/lector lenguado de Maier, aunque no sólo asociando al paisaje y a sus pensamientos aquello que ha leído en otros textos (debido a que también padece el “mal de Montano"), sino las particularidades de los diversos spleen que le provoca mirar dentro y fuera del vagón.

En Dublinesca, Riba se marcha a Lyon para intentar escribir una teoría de la "novela por venir", que se basa en los puntos esenciales de lo que Julien Gracq pensaba que debía ser dicha novela: "intertextualidad; conexiones con la alta poesía; conciencia de un paisaje moral en ruinas; ligera superioridad del estilo sobre la trama; la escritura vista como un reloj que avanza" (15).

No será otro el programa que Maier echa a rodar en Material rodante.

\section{Momentos patéticos y disfóricos: el intermezzo como fundamento}

Además de su sabido trabajo literario, la labor crítica de Gonzalo Maier lo confirma como un lector atento y, sobre todo, expectante de la literatura chilena contemporánea. ${ }^{3}$ De esta manera, advierte como imprescindible el abrir una varilla del

2 Se recordará que Roland Barthes tipifica, en "Introducción al análisis estructural de los relatos", que todo lo anotado en un relato puede ser "funcional", aunque no en el mismo grado. Hay funciones llamadas cardinales que constituyen nudos de la historia (articulan su armazón y su posibilidad de progresión); mientras que otras funciones, llamadas catálisis, sólo complementan a las primeras: "Para retomar la clase de las Funciones, digamos que sus unidades no tienen todas la misma 'importancia'; algunas constituyen verdaderos 'nudos' del relato (o de un fragmento del relato); otras no hacen más que 'llenar' el espacio narrativo que separa las funciones 'nudo"' (Barthes 20). Diríamos que en Material rodante las acciones cardinales (actos) quedan deliberadamente afuera, mientras las catálisis (intermezzos) son aquellas que le dan sustancia e identidad al relato; sustancia siempre mestiza, es decir, no sólo narrativa, sino historiográfica, ensayística, diarística, etc.

3 Cf. "Mientras tanto en la tierra: ironía y simulacro en ;Arre! Halley jarre!, de Elvira Hernández" (Revista Alpha 71, 2015), "Fuera de foco: ironía y fotografía en Estrella distante, de Roberto Bolaño" (Re- 
abanico que, si bien es posible evidenciarla en ciertas zonas de la obra de Alejandro Zambra o Álvaro Bisama (los comentarios a la manufactura misma del libro que el lector tiene entre las manos), el intento es aún tímido o no del todo funcional en las letras chilenas. No se trata de erigir una enorme catedral metaficcional al modo de Vila-Matas, pero sí una casa bien cimentada que se enriquezca con cada entrega y que presente en muchos sentidos contrapuntos con las tendencias dominantes en Chile (entre otras, la mentada "literatura de los hijos").

En Material rodante hay una clara conciencia metaliteraria y, por lo tanto, rigurosamente reflexiva con todo el material usado para erigir la historia: "Hasta el momento estos apuntes intermitentes han sido un ejercicio privado más o menos extranjero. .." (56). Como en los libros de Vila-Matas, se trabaja con varios recursos posmodernos ${ }^{4}$ siendo uno de los principales la exhibición del proceso creativo. Es decir, se trata de una novela que se está haciendo a medida que se lee, que va avanzando y deteniéndose, como un tren de trayectos a ratos firmes, a ratos giróvagos. Así, volviendo a la analogía de la estructura del montaje dramático, en este trayecto —el del viaje entre las dos ciudades y también en el de la escritura- las escenas, como tal, importan poco (la vida cotidiana del narrador en Lovaina; su trabajo en Nijmegen; las particularidades de su matrimonio; su pasado en Chile, etc.), teniendo primer orden de importancia los intervalos. El narrador de Maier parece afirmar que todos esos momentos donde la acción queda suspendida (momentos patéticos o disfóricos, ${ }^{5}$ para nombrarlo en términos poéticos y establecer, así, correspondencia

vista Neopbilologus 100, 2016); "Bruce Lee en Chile: ironía y parodia en Fuenzalida de Nona Fernández" (Quarterly Journal in Modern Literatures 71, 2017); “'Ni ahora ni nunca': diatriba y pensamiento positivo en Contra los hijos, de Lina Meruane" (Revista Neophilologus 104, 2019), entre otros.

4 Véase Javier Aparicio Maydeu, Lecturas de ficción contemporáneas: "Escritura libérrima sin cabier de notes. Saltos, elipsis, incoherencias internas, reiteraciones, alteraciones del work in progress en función de las circunstancias externas a la propia obra” (32). Asimismo, puede verse: María del Pilar Lozano Mijares, "Cap. II. Posmodernidad y novela", en La novela española posmoderna (2007): "En cuanto al autor posmoderno, ya no es un creador omnipotente. capaz de hacer surgir un microcosmos ex nibilo, sino . . a alguien que se identifica, en su proceso de conocimiento, con lo errante, la incertidumbre de la exploración y del descubrimiento; una conciencia que se pregunta acerca del ser de las cosas y del mundo que le rodea, un ser abocado a la búsqueda ontológica" (168). Para una clasificación aún más rigurosa de los recursos narrativos posmodernos, es posible consultar: Lucien Dällenbach, Le récit speculáire (1977) y Linda Hutcheon, A Poetics of Postmodernism (1988).

5 Jean Cohen llama noéticos a los momentos de gran intensidad semántica en la enunciación poética; mientras que a aquellas instancias de descomprensión les denomina patéticas: "A partir de una oposición fenomenológica de los dos lenguajes como "intensidad" vs "neutralidad", se distinguirán dos tipos de sentido llamados "noético" y "patético", ambos presentes, de manera virtual, en las expresiones de la lengua, a partir de los dos componentes de la experiencia en que se origina el sentido" (33). Como señala 
con el punto 2 de la "teoría de la novela" por venir de Samuel Riba, en Dublinesca) son los momentos en los que se encuentra, en realidad, lo imprescindible: "[L]a clave de la perfección estaba en la ausencia de movimiento. . Todo lo que requiere moverse es imperfecto porque, claro, necesita algo" (77). Y esta es la paradoja: los actos, aunque parecen estar plenos de acción y dinamismo, permanecen igual, sin casi variación; mientras que los intersticios o intermezzos están sometidos a un intenso principio de incertidumbre donde la existencia se vuelve más interesante:

[L]o curioso de este recorrido, su principal gracia, es que no hay novedad. Es siempre igual. Calcado. Pasan los años, presidentes, guerras y cortes de pelo, pero este viaje que repito todas las semanas, desde hace ya un par de años, es siempre el mismo. No hay paisajes ni países nuevos, pero en cualquier detalle, por mínimo que sea, incluso en la sonrisa falsa de la revisora de boletos, sigue intacta la posibilidad de romper la costumbre, lo normal. En otras palabras, de salir realmente de viaje (12).

En esa posibilidad (y sólo posibilidad, sin concreción) de romper la costumbre se fundamentará la novela. El narrador comprende pronto que si bien para la obra de la vida cotidiana (la de los actos) ya se tienen aprendidos los parlamentos, se debe buscar y ensayar otro papel protagónico, el que se interpretará en la obra de los intermedios. Tiene tal intensidad este reconocimiento que luego de citar a Joseph Brodsky, "el mimetismo es la moneda más preciada de todo viajero" (13), Maier emplea otro recurso literario, el de desdoblarse como actor para poder enunciar todo lo que vendrá posteriormente: "Durante su primera estancia en Venecia, [Brodsky] iba vestido como él creía que se vestían los italianos. Es decir, en blanco y negro, como en las películas de Antonioni ... Mientras afuera el campo se acostumbra a la primavera, me autoevalúo a ver cuánto me mimetizo y qué película trato de representar" (13).

En esto también se alude intertextualmente al Doctor Pasavento, de Vila-Matas, quien irá mimetizándose como actor en diversos intermedios de la novela hasta llegar a una zona disfórica o patética por excelencia: la desaparición. No obstante, aunque en Material rodante también está en estado latente la pulsión de desaparecer, el narrador de Maier no acabará encarnando a Robert Walser, como sí Pasavento,

también Juventino Caminero, reforzando el punto: "Los grandes poetas obedecen en su práctica como creadores de realidades subjetivas al control objetivo de los universales del sentimiento, de acuerdo con un movimiento pendular, que se materializa en dos direcciones contrapuestas, las cuales pueden ser denominadas euforia y disforia. Dentro de estos extremos se aloja una serie indeterminada de tonalidades" (275). 
hundido en la nieve, sino aceptando que el único modo de existencia es repetir el bucle del viaje (en un recurso narrativo que la teoría posmoderna ha dado a llamar beterarchy $y^{6}$ y esperar a que las cosas, en los intersticios, puedan darse de modo distinto si se vuelve a tomar el tren en la estación de Lovaina (es decir, volviendo al punto de partida).

Aquí hay otro recurso de la narrativa posmoderna, comentado por Lucien Dällenbach como "bucle programático", donde la historia se riza, "no dejándole más porvenir que lo ya sucedido. Todo el margen de maniobra que se consiente ahora al relato estriba en volver sobre el reflejo anterior y someterlo a catálisis, respetando el programa que anuncia y entrando en el detalle de su contenido" (75). De este modo, el texto "reúne episodios y rasgos dispersos cuya percepción casi simultánea, en el umbral del libro, no deja de influir en su modo de desciframiento: advertido de un recorrido que conoce sintéticamente, el lector sabe hacia dónde se dirige y puede, sin titubeos, imponer escansiones en su itinerario, identificar los tiempos fuertes en su marcha, controlar su avance" (75). Añadiríamos una variación a esta teoría de la ficción posmoderna de Dällenbach: no sólo el lector, sino también el autor sabe hacia dónde se dirige y, por ello, impone dichas escansiones: "A fin de cuentas", señala en narrador de Maier, "este no es un viaje hacia un destino desconocido, sino la repetición de uno" (14). Y luego lo confirma, más adelante:

A los niños, me contaba una vez un amigo, les gusta escuchar siempre la misma canción, o ver siempre la misma película, porque a diferencia de los lectores de novelas policiales prefieren la seguridad, el terreno plano y conocido. Nada que tenga sorpresas ni sobresaltos. Ignoro si sea cierto, pero esa misma quietud, por ejemplo, permite ficciones como la que sucede cuando el revisor pide los boletos o pregunta si uno sabe en qué andén hay que cambiar (60).

Por lo tanto, el papel que toca interpretar es el de un actor que no se mueve, pero escudriña; un actor al que mueve el tren, pero que intentará realizar la mínima oscilación con el fin de poder enunciar con más exactitud los fragmentos de esta novela rizada. Concentrado en interpretar su rol activamente, el actor de los actos del drama está demasiado concentrado en hacer avanzar el argumento hacia la escena siguiente. En cambio, el actor de los intermedios tendrá, como decía Riba que decía Gracq, la responsabilidad de testificar un "paisaje moral en ruinas" desde la ventanilla de un vagón.

6 "Una estructura recursiva llevada al límite nos conduce a una beterarchy o "heterarquía", una estructura de múltiples niveles en la que no existe una diegesis principal, puesto que no se puede discernir qué nivel es jerárquicarmente superior, cuál es secundario" (Lozano Mijares, 176). 


\section{El observador cuántico}

No es casualidad, pues, que la novela de Maier tenga a un observador dentro de un tren (uno de los tópicos de la física cuántica), mismo que contrasta un espacio que hay allí afuera con otro que se percibe dentro del transporte, y un tiempo que es el del presente, pero que no parece consecuencia directa de un pasado ni menos un antecedente de lo que vendrá. ${ }^{7}$ Sólo de este modo es posible entender que el narrador de Gonzalo Maier encarne (con cierto distanciamiento, con cierta ironía) a aquel observador de la experimentación cuántica: "Antes de la teoría de la relatividad, todo mundo suponía que tanto el pasajero que va en un ferrocarril como el espectador que está a un lado de la vía y un hombre que se encuentre en Marte, utilizaban un mismo tiempo", explica el físico británico Paul Davies.

El tiempo newtoniano es absoluto y universal; no es modificado por el estado de movimiento del observador y es fijo en todo el universo. Ahora se sabe que es errónea esta concepción del tiempo como telón de fondo o marco de referencia fijo con respecto al cual se pueden medir los acontecimientos. No existe un 'mismo' momento universal (71).

De esta manera, entramos en la comprensión de Material rodante como una novela donde cada fractalidad, cada espacio intersticial, no solamente opera como escena o anécdota fija, sino como condición de posibilidad para la estructuración de cualquier otra historia posible en caso de que el narrador desee desarrollarla. Sólo gracias a este viaje elíptico en tren es posible que, potencialmente, en otros textos se amplíen o contraigan las historias de un trío amoroso con Tony, un amigo italiano, y Aila, una amiga turca; la del pasajero que lee mamotretos en la vida dinámica del tren y que luego es entrevisto bajando una escalera, en la vida estática de la ciudad; la de los ciclistas que se entrenan en las montañas holandesas con energía insensata; o la más elaborada y comentada historia de la araucaria chilena, traída de modo clandestino a Europa. El asunto es, como se ha analizado, que el narrador no va a querer darle planteamiento y desenlace a estos núcleos argumentales. Cuando el narrador señala que "los viajes efectivamente ofrecen vidas paralelas, oportunidades únicas que no se darán en otras partes” (11), lo que está marcando es que la percepción del espacio y del tiempo, tanto en el tren como en el acto de escribir, es fractal, irregular, y corre siempre el riesgo de descentrarse de la premisa principal.

7 "En cuanto al tiempo, ya he ido adelantando la confusión de pasado y futuro, fundidos en un presente totalizador, en el estudio de la novela historiográfica. El eclectismo al que tantas veces me he referido como rasgo dominante del posmodernismo implica un cambio en la conciencia del tiempo, que parece ser absorbido por el espacio" (Lozano Mijares 173). 
Resultará entendible, entonces, con un narrador así, que el relato abandone la pretensión de una novela al uso (de estructura progresiva), y también el de un diario de viajes (impresiones de lo visto), y tenga una naturaleza ecléctica e inestable porque no hay acción, sólo reacción contemplativa. ${ }^{8}$ Esto resulta patente cuando se habla, en Material rodante, de los procesos de automatización de la vida cotidiana. En caso de querer usarla (acción), la máquina de dulces en la estación de Roosendaal se traga las monedas, pero ofrece un espectáculo singular, mucho más interesante que haber conseguido alguna golosina, cuando se le mira (contemplación) desde la ventanilla del tren: "[V]eo a mujeres y hombres zamarrear la máquina con la esperanza de que caiga cualquier cosa que recompense las monedas perdidas. Hay tardes en que mirar puntualmente ese espectáculo, desde un asiento metálico y frío, no es un mal modo de recuperar hasta el último céntimo" (26). "El telón de fondo de este recorrido - y, en particular, de las estaciones de paso de un tren a otro- es una suma de letreros plásticos y nombres de fantasía que terminan siendo familiares" (20), señala en otro momento, marcando la focalización en las estaciones más que en las ciudades, en los intermedios más que en los actos.

Con la infalibilidad y circunspección de las líneas ferroviarias europeas como telón de fondo, el tren en el que viaja este narrador autodiegético daría cuenta, entonces, de un sistema estable pero que pronto va desorganizándose entrópicamente:

El punto de partida es Lovaina (Leuven en holandés y Louvain en francés), una vieja ciudad universitaria de monjas y curas que está casi en el centro de Bélgica, y el punto de llegada es Nimega (Nijmegen), la capital jipi de Holanda. Son 180 kilómetros que he recorrido más o menos trescientas setenta y seis veces, en un sentido y en otro ... (14).

En caso de que fuera un viaje lineal, este trayecto, y por ende esta novela, representaría una suerte de bildusgroman donde el personaje va de un conservadurismo

8 Lo dice Lozano Mijares, también, como recurso prototípico de la novela posmoderna: “¿Qué ocurre cuando el concepto de realidad comienza a ser percibido de forma caótica? Entramos en el paradigma estético de la modernidad: lo real contingente es fragmentación, es caos, pero la subjetividad del creador, su conciencia, podrá reorganizarlo y trascenderlo —o, al menos, ese será su objetivo. La estructura de la novela, para guardar coherencia con este cambio, se romperá, pero la conciencia narradora flotará sobre los pedazos. Demos un paso más: ¿qué ocurre cuando el sujeto que narra percibe no sólo la realidad como fragmentación, sino también su propia subjetividad como caos? Aparece la novela posmoderna, la ironía cínica, la ontología problemática: ya no se trata sólo de cómo puedo yo conocer el mundo, penetrarlo, reorganizado, sino de cómo, una vez asumida la imposibilidad de cualquier explicación, me enfrento a él, vivo en él" (155). 
evidente (situación brindada por la imagen del clero belga) al encuentro con la liberación sexual y vital (dada por la mención al hipismo holandés) y con un entorno más sofisticado (los negocios van adquiriendo mayor refinamiento, pasando de fotomatones y cafeterías con "medialunas mediocres" (21) a Starbucks, florerías y tiendas de discos). Podría interpretarse, también, como la transformación de un chileno (en términos de idiosincrasia, un sujeto carca, anodino, con cierta mentalidad insular debido a la distancia de Chile con el resto del mundo) a un "ciudadano universal", para usar un eufemismo, que quiere, justo, mimetizarse con los usos y costumbres europeos. Pero pronto esta posibilidad se abandona y hay un interés no por lo que ocurre fenoménicamente en este viaje (que, por circular, cancela la posibilidad de una transformación más dramática del personaje), sino por el modo en que este observador cuántico superpone su percepción al paisaje real, asunto claro en la afirmación:

Mi Holanda no es una Holanda que haya descubierto leyendo novelas ni echado sobre las butacas de un cine ..., sino una Holanda estrictamente personal y privada. Una que me dedico a inventar arriba de un tren, aprendiendo a comer con queso gouda y a usar impermeables. Tal y como si este viaje fuera una novela. Una novela que no parece novela, tal como mi Holanda no se parece ni siquiera un poco a Holanda. (15)

Toda posibilidad, entonces, de cuaderno de viajes y de novela tradicional queda desestimada. Hay, y para abonar más a la teoría posmoderna (Baudrillard mediante), una yuxtaposición de planos, donde la Holanda y la Bélgica de los "territorios" dan paso a la de los "mapas" particulares de un observador que se siente siempre desajustado, extranjero, poco chileno.

\section{Historia de un piñón: una chilenidad precaria}

Ahora bien: Linda Hutcheon señalaba, a finales de los años 80, que una de las características más marcadas de la narrativa posmoderna era la "metaficción historiográfica", "those well-known and popular novels which are both intensely self-reflexive and yet paradoxically also lay claim to historical events and personages" (5). El cruce entre un discurso histórico, en términos de hechos comprobados, con la constatación de que en el mismo texto salen a flote los pormenores técnicos de la ficción, ha permitido que varios novelistas critiquen una macroestructura como la Historia, con mayúsculas, al ser narrada por quienes se apropiaron de un lugar de enunciación a conveniencia, y, por lo tanto, discriminaron testimonios, documentos y sujetos que no estaban en consonancia con lo narrado. La ficción posmoder- 
na, pues, rescata hechos históricos marginales, aparentemente baladíes, y lo hace con una fuerte carga documental, por un lado, y reflexiva, por otro.

En el caso de Material rodante, la metaficcion historiográfica se trabaja en términos de parodia y constituye una de las líneas que se sostienen con mayor ahínco en el libro, primero por razones anecdóticas y después, como se verá, para reforzar una precaria identidad.

La historia ya ha sido comentada: por la ventanilla del tren que va de Lovaina a Nijmegen, la visión periférica del lenguado repara de súbito en una araucaria, el árbol sagrado de los indígenas mapuches y pehuenches: "Nos separaban solo quince metros y una ventana. Como no era gran cosa, aproveché de mirarla sin pudor ni vergüenza, de arriba abajo y sin creérmelo mucho: era una araucaria calcada a las que vi mil veces en los bosques del sur de Chile" (18). La anomalía provocada por un objeto del propio terruño desordena la cuadrícula impecable de la cotidianidad europea. El narrador, primero, desea seguir manteniendo a distancia el asunto del arraigo - "nunca he tenido mayor interés en los mapuches y, en general, las culturas (aborígenes o no) y los discursos nacionalistas me aburren tanto que corro el peligro de morir atorado a bostezos" (19)—, pero luego descubre que "una obsesión un poco ridícula" (19) se apodera de él. Para responderse qué hace una araucaria ahí, en Holanda, encarga libros por The Book Depository. Da con la historia de Archibald Menzies, botánico escocés que, a bordo del Prince of Wales, en el siglo XIX llega de excepción a Valparaíso, Chile. Se entera, luego, de que este Menzies tiene, en Santiago, una recepción con Ambrosio O’ Higgins, capitán general, en cuyo banquete se incluyen piñones, el tan preciado fruto de la araucaria. $\mathrm{Y}$, finalmente, averigua que los bolsillos del botánico van repletos de piñones, más otras ciento treinta y siete especies exóticas, en su regreso a Europa.

Hay, entonces, en el episodio de la araucaria un acto. O, mejor dicho, la posibilidad de reconstruir ese acto: el presente, la araucaria de Etten-Leur, Holanda, es consecuencia de un evento del pasado que, probablemente, sólo este personaje de Material rodante se esfuerza por saber y atesorar. Esto no sólo provoca en él una satisfacción personal —algo patética, que pronto decaerá-, sino que lo insufla de ánimos para, incluso, escribir la historia de la araucaria de Menzies, un borrón de pintura chilena en el enorme cuadro de la campiña europea: "Durante un tiempo intenté escribir esta historia como una novela de época y no como estos apuntes inútiles y dispersos" (110). Sin embargo, en Kew Gardens, Londres, (donde se encuentran otros ejemplares de araucarias y que el narrador, obsesionado con la historia de su botánico, piensa también de su procedencia) se entera por Mary, una 
guía de los jardines, que en realidad todo su trabajo historiográfico, y sus intenciones como novelista serio, no serán más que mitología:

Yo, que creía haberlo leído todo sobre el árbol, le conté el cuento de Menzies y de dónde venía el ejemplar que teníamos frente a nuestras narices. Pero apenas di por terminada mi cátedra, Mary me miró con cara de qué hombre tan pedante y me dijo que la historia de la araucaria no era ni tan naturalista ni tan ilustrada como yo la contaba, sino que parecía también una novela policial de esas con un final inesperado.

Las semanas siguientes por supuesto, las gasté buscando libros viejos y confirmando que lo que ella decía era cierto.

Porque lo era (108).

Las araucarias de Menzies llegaron, efectivamente, a los Kew Gardens, pero al poco tiempo murieron. Las que están exhibidas en Londres se le deben a dos cazadores pendencieros, los hermanos William y Thomas Lobb, historia que sólo confirma una arista más del saqueo europeo en América y no una aventura épica de cazadores de fauna exótica. Con cierta ironía, el narrador quiere reivindicarse: "A las dos horas me cansé de jugar al hipócrita porque nada me aburre más que las novelas históricas" (110), y vuelve a hundirse en su condición de excritor. Coincidimos, entonces, con Roberto Careaga, cuando interpreta esta actitud más como reflexiva que desidiosa: "Él dice que es aburrimiento, pero creo que la razón porque la Maier no escribe la historia de los hermanos Lobb y sí Material Rodante es por una manera de entenderse con la literatura y, quién sabe, acaso también con el mundo: dejándose llevar" (párr. 18).

¿Qué quedará, entonces, como propiamente identitario, como propiamente chileno cuando todo el paisaje, incluso lingüístico — “me he pillado hojeando diarios y revistas en holandés e incluso en frisón. . ., me concentro en algo que creo reconocer, en algún sintagma ligeramente familiar, y en un momento, como si me tiraran agua fría, caigo en la cuenta de que no estoy entendiendo nada" (27) se desestabiliza? Al parecer, los únicos piñones que permanecen auténticamente plantados en Europa serán los del lenguaje. Es allí, en los matices que el habla le hace a la lengua, donde pueden notarse realmente los rasgos identitarios, alguna idiosincrasia, cierto orgullo nacionalista. Es por esto que Maier puebla Material rodante de expresiones muy chilenas, muchas de ellas provenientes etimológicamente del mapudungún, casi como un modo de inseminar de piñones unos surcos tan belga-holandeses. Aquí, todas las cursivas son nuestras: "Llevan el pelo corto y 
una pistola piñufla colgando del cinturón" (20); "se necesita un pichintún de vuelo para alcanzar kilómetros y kilómetros" (49); "le agarra el poto y le da un beso" (52); "cerrar los ojos con un libro sobre la guata" (75); "[a]penas me cayó la teja corrí patéticamente por el andén" (76); "otros se quitan el impermeable y algunos derechamente la polera e incluso los zapatos" (103), etcétera. La cbilenidad, por ende, no parece habitar en otro sitio que en los giros lingǘsticos recursivos, iterativos, así como esta narración no se comprende fuera del bucle programático, centrado en los intermezzos de un viaje en tren.

Antes de finalizar, es prioritario señalar un par de cosas. Dice el narrador: "uno aprende a leer ya no instrucciones prácticas ni libros llenos de jirafas y leones sonrientes, sino cosas inútiles como cuentos y novelas de aventuras. Cuando llega ese punto, creo, es cuando uno en realidad aprende a leer" (2015: 28). Gracias a las reflexiones literarias y metaliterarias que se abren entre los fragmentos de Material rodante, habría que incorporar un eslabón adicional, un escalafón más alto, que es la lectura de aquellos cuentos y novelas que expulsan de sus páginas la aventura para centrarse con plenitud en la contemplación: "[E]l problema del mundo moderno ... no es más que el exceso de movimiento" (79). Se piensa inmediatamente en Enrique Vila-Matas, el referente más directo de Maier. Pero en la página 88 hay un intento por establecer un "canon del deseo", al decir de Borges; es decir, un sistema literario con otros escritores reflexivos, y por ende más perfectos, con los que el autor quiere ser asociado. Y aquí campean desde Fabián Casas, Claudio Bertoni, Vivian Abenshushan y Luigi Amara hasta Coetzee, Houellebecq, Chesterton y Charles Lamb. ${ }^{9}$ Vila-Matas mismo decía que un escritor puede tener muchos mentores, pero un solo maestro, y que en su caso era Sergio Pitol. ${ }^{10}$ Lo mismo puede aplicarse a Gonzalo Maier, en este reconocimiento de eslabones de la larga cadena de escritores posmodernos y metaliterarios del siglo XXI, por lo que la academia chilena tiene todavía una asignatura pendiente: realizar un análisis intertextual profundísimo entre los libros de Gonzalo Maier (al menos, los

9 "Sobre los rieles que van de Lovaina a Nimega, se puede leer: El secreto de Joe Gould, Entrerrianos, El portero y el otro, Una habitación en Holanda, Breves apuntes de autoayuda, Elizabeth Costello, La tierra prometida, Un trago antes de la guerra, Calle de las tiendas oscuras, Bouvard y Pécuchet, El verano sin hombres, El frente ruso , Libertad, Al pie de la escalera, The Collected Writings of Joe Brainard, En la belleza ajena, El mapa y el territorio, Se acabó el pastel, Celos, 222 patitos, Lennox, Extra lives, Mi perra Tulip, Rápido, antes de llorar, The Portable Charles Lamb, Horla City y otros, Las cascadas, Correr tras el propio sombrero, Desubicados, El ladrón de orquídeas, Monkey Puzzle Man, La escuela del aburrimiento, Una habitación desordenada, Las encías de la azafata, Ensayos de Elia” (88-89).

10 Cf. Enrique Vila-Matas, "Plan para el más allă": "[M]e convertí en escritor gracias a Pitol y mi afición definitiva por la cultura la produjo el propio Sergio" (36). 
que van desde El destello hasta El libro de los bolsillos) y los de Vila-Matas que se encuentran entre Bartleby y compañia (1997) y Dublinesca (2010).

Y, en segundo lugar, derivado de lo anterior y de todo este estudio: la obra portátil de Gonzalo Maier es una buena noticia porque permite encontrar, en medio de la bruma de la "literatura de los hijos" (degastada, repetitiva, de alcances poco claros), una alternativa, una posibilidad de buscar el arraigo en territorios extranjeros que no son los mitificados por la novela del exilio (París, Estocolmo, Londres), pero donde también es posible hallar ciertos ramalazos de chilenidad. Como "la memoria de los niños al final es una memoria heredada, de juguete" (91) (y con esta frase parece darse carpetazo a todos esos libros de corte narcisista que, según, tenían una historia que contar, alternativa a la de sus padres), la literatura Maier es una invitación a entrar de forma más madura en la novela breve intersticial, extravagante y perfecta; como esa araucaria que corta el muy poco sorpresivo paisaje europeo. 


\section{Obras citadas}

Aparicio Maydeu, Javier. Lecturas de ficción contemporánea. De Kafka a Ishiguro. Madrid: Cátedra, 2008.

Barthes, Roland. «Introducción al estudio estructural del relato» en Roland Barthes, et al., Análisis estructural del relato. Trad. Beatriz Dorriots. México: Coyoacán, 2006: 9-44.

Bhabha, Homi K. El lugar en la cultura. Trad. César Aira. Buenos Aires: Manantial, 2002.

Caminero, Juventino. Poesía española. Siglo XX. Capitulos esenciales. Kassel: Reichenberg, 1998.

Careaga, Roberto. «El oleaje autobiográfico». Revista digital Paniko, abril 2016. Disponible en: <https://paniko.cl/el-oleaje-autobiografico/>

Cohen, Jean. El lenguaje de la poesía. Teoría de la poeiticidad. Trad. Soledad García Moutón. Madrid: Gredos, 1982.

Dällenbach, Lucien. El relato especular. Trad. Ramón Buenaventura. Madrid: Visor, 1991.

Davies, Paul Chambers W. El espacio y el tiempo en el universo contemporáneo. Trad. Roberto Heller. Ciudad de México: Fondo de Cultura Económica, 1982.

Espinosa, Patricia. «Material rodante, de Gonzalo Maier». Las Últimas Noticias, 18 de diciembre de 2015: 92.

Genette, Gérard. Palimpsestos. La literatura en segundo grado. Trad. Celia Fernández Prieto, Madrid: Gredos, 1989.

Hutcheon, Linda. A Poetics of Postmodernism. History, Theory, Fiction. Nueva YorkLondres: Routledge, 1988.

Lozano Mijares, María del Pilar. La novela española posmoderna. Madrid: Arco Libros, 2007.

Maier, Gonzalo. Leyendo a Vila-Matas. Barcelona: Minúscula, 2011. Libro electrónico. . Material rodante. Barcelona: Minúscula, 2015. 
Teoría del intermezzo: formas intersticiales de leer Material rodante...

Felipe Ríos Baeza

Sebastián, Pablo. «Materialrodante, de Gonzalo Maier». La República (Perú), 6 de abril de 2016. Disponible en: <https://www.republica.com/libroficcion/2016/04/06/ material-rodante-de-gonzalo-maier/>

Solano, Francisco. «Gonzalo Maier en movimiento». «Babelia», El País, 17 de julio de 2015. Disponible en: <https://elpais.com/cultura/2015/07/16/ babelia/1437055054 214467.html>

Vila-Matas, Enrique. Bartleby y compañia. Barcelona: Anagrama, 2001.

_.. Doctor Pasavento. Barcelona: Anagrama, 2005. . «Plan para el más allá», El País, 17 de enero de 2006: 36.

. Dublinesca. Barcelona: Seix-Barral, 2010. 